This is a peer-reviewed, accepted author manuscript of the following research article: Khajeian, A., Mahmoudi, A. H., \& Mehmanparast, A. (2019). Shot peening effects on residual stresses redistribution of offshore wind monopile multi-pass weldments. Marine Structures, 66, 106-120. https://doi.org/10.1016/j.marstruc.2019.03.006

\title{
Shot Peening Effects on Residual Stresses Redistribution of Offshore Wind Monopile Multi-pass Weldments
}

\author{
A. Khajeian ${ }^{a}$, A. H. Mahmoudi ${ }^{b,}{ }^{*}$ and A. Mehmanparast ${ }^{c}$ \\ a, b Mechanical Engineering Department, Bu-Ali Sina University, Hamedan, Iran \\ ${ }^{c}$ Offshore Renewable Energy Engineering Centre, Cranfield University, Cranfield, Bedfordshire \\ MK43 OAL, UK \\ *Corresponding author. E-mail addresses: a.h.mahmoudi@gmail.com
}

Keywords: Redistribution of Residual stresses, Multi-pass weld, Shot peening, Offshore monopile

\begin{abstract}
In some industrial applications, welding is the only alternative to join different parts. However, the major problem in welded structures is the tensile residual stresses that are inevitably produced during welding process. Surface tensile stresses can threaten the performance of the weldments as they act as an accelerant in fatigue crack initiation and failure. Shot peening is a well-known method which can enhance weldments' fatigue performance and longevity by inducing surface compressive residual stresses in order to eliminate or limit tensile residual stresses.

In this study, the effect of shot peening on redistribution of multi-pass welding residual stresses was numerically and experimentally investigated on very large components typical of welded joints used in offshore wind turbine monopiles. Finite element studies were carried out using 3D welding models and random shot peening analyses. Moreover, extensive finite element analyses were conducted to study the effect of model dimensions and the number of passes on prediction of welding residual stresses. Interesting set of results showed that shot peening can be advantageous even for large components with multi-pass welded joints. Additionally, reducing the number of weld passes in finite element models could considerably lower the computational time without affecting the accuracy of results at surface regions of the models.
\end{abstract}

\section{Introduction}

Nowadays, fusion welding has been considered as a dominant joining process in various industries. Monopiles, the most widely used foundations for supporting offshore wind turbines in shallow waters [1-3], are the examples of structures that are produced by fusion welding. These giant cylindrical structures are made from thick steel plates that are longitudinally and circumferentially welded by a large number of weld passes. The existence of unwanted tensile residual stresses which unavoidably produced in welded structures as a consequence of cyclic thermal loading and non-uniform temperature distribution $[4,5]$ has become a growing concern for the most welded sections due to their detrimental effects on crack initiation and its propagation. Therefore, a great number of researches were performed on a wide variety of techniques that have the capability to remove or diminish these stresses. Post-weld heat treatment (PWHT) [6], vibration stress relief 
(VSR) [7] and laser shock peening (LSP) [8] are only few examples of these methods. Meanwhile, shot peening has also turned out to be among the most efficient and accessible post-weld treatment techniques. In this method, surface is peened by high velocity shots and creation of plastic regions followed by inducing compressive residual stresses beneath the surface. Bellow et al.[9], Bertini et al. [10] and $\mathrm{Li}$ et al. [11], all evaluated the effect of shot peening and other post-weld treatment techniques on welding residual stresses and fatigue behaviour. All these researches concluded that shot peening process could effectively improve the fatigue behaviour of the weldments by introducing a uniform compressive residual stresses distribution on the surface [9-11]. Same beneficial results were also confirmed by other researchers [12, 13]. Gan et al. [14], experimentally studied the effects of different shot peening intensities on fatigue lives of T-welded joints. Dieng et al. [15] also studied the effect of shot peening on residual stresses redistribution in T-welded joints by developing finite element models and experimental measurements.

In almost all above researches, investigating the effects of shot peening on redistribution of welding residual stresses was restricted to relatively thin plates with few weld passes. In addition, in most literatures $[9-11,14]$ this effect was only experimentally studied or the shots arrangements in numerical studies [15] did not replicate the real random positioning. Nevertheless, a combination of numerical and experimental studies on the effect of shot peening on multi-pass butt-joints' residual stresses distribution has not been developed, yet. Due to its extensive applications, numerous studies were carried out on shot peening process and various finite element models were also proposed to properly simulate this process. An axi-symmetric, single impact model was used by Mori et al. [16] by considering plastic deformation for both the shots and the target. Meguid et al. [17] used quarter models (with two symmetry planes) to simulate the single and double impacts. In a study by Gualiano [18], some peening parameters were studied using a model included five shots which consecutively hit the surface. Meguid et al. [19] and Majzoobi et al. [20] used symmetry cells to study the shot peening process, numerically. Miao et al. [21], Hassani-Gangaraj et al. [22] and Ghasemi et al. [23] were all proposed the shot peening random positioning models which were more similar to the real peening process.

Since the repetition of thermal cycles results in more complex residual stresses distribution, the treatment of residual stresses in multi-pass weld sections is more important. The present study is concerned with this issue in multi-pass butt-welded joints with a large number of weld passes in thick sections and includes both numerical and experimental investigations. The under studied samples in experimental procedures included specimens used in construction of offshore wind turbine monopiles. Comprehensive finite element studies were also performed to simulate the multi-pass welding process and the subsequent shot peening process using random shot peening models. Furthermore, several finite element models were developed to study the effects of pass numbers and dimensions reduction on predicting residual stresses distribution in numerical studies of the multi-pass welding process for huge samples. Additionally, the effects of weld toe grinding and the consecutive shot peening process was experimentally evaluated. 


\section{Experiments}

\subsection{Material}

The material used in the present study was $\mathrm{S} 355 \mathrm{G} 10+\mathrm{M}$ steel, a grade of structural steels which is commonly employed in offshore industry. The chemical composition of this material is presented in table $1[24]$

Table 1. Chemical composition of S355G10+M (wt\%) [24]

\begin{tabular}{ccccccc}
$\mathbf{C}$ & $\mathbf{S i}$ & $\mathbf{M n}$ & $\mathbf{P}$ & $\mathbf{S}$ & $\mathbf{N}$ & $\mathbf{C u}$ \\
\hline 0.061 & 0.28 & 1.58 & 0.013 & 0.0007 & 0.0041 & 0.254 \\
\hline $\mathbf{M o}$ & $\mathbf{N i}$ & $\mathbf{C r}$ & $\mathbf{V}$ & $\mathbf{N b}$ & $\mathbf{A s}$ & $\mathbf{S n}$ \\
\hline 0.006 & 0.342 & 0.034 & 0.001 & 0.022 & 0.003 & 0.001 \\
\hline $\mathbf{T i}$ & $\mathbf{P b}$ & $\mathbf{B}$ & $\mathbf{S b}$ & $\mathbf{C a}$ & $\mathbf{B i}$ & $\mathbf{A l}-\mathbf{T}$ \\
\hline 0.003 & 0.0 & 0.0003 & 0.001 & 0.0028 & 0.0001 & 0.032 \\
\hline
\end{tabular}

In order to obtain the stress-strain curves of different regions of the welded section, a tension test was performed on a dog-bone specimen using a Dantec Q-400 digital image correlation (DIC) system. The test was carried out at room temperature and its displacement rate was selected to be $1 \mathrm{~mm} / \mathrm{min}$. It is worth noting that the tensile test specimen was cut from the welded joint and included all three main welding regions, namely the base metal, the weld metal and the heat affected zone (HAZ). Fig. 1 and Fig. 2 illustrate the tensile test specimen and the engineering stress-strain curves of the mentioned regions obtained from the DIC tensile test, respectively [24]. Fig. 2 clearly reveals the differences between the tensile behaviour and mechanical properties of different weld regions. According to Fig. 2, the Young's modulus and the $0.2 \%$ proof stress for the base metal are around $196 \mathrm{GPa}$ and $455 \mathrm{MPa}$, in turn. It is worth noting that due to the lack of other properties of this material, the temperature dependent thermo-mechanical properties of S355 steel were used in finite element simulations [25].

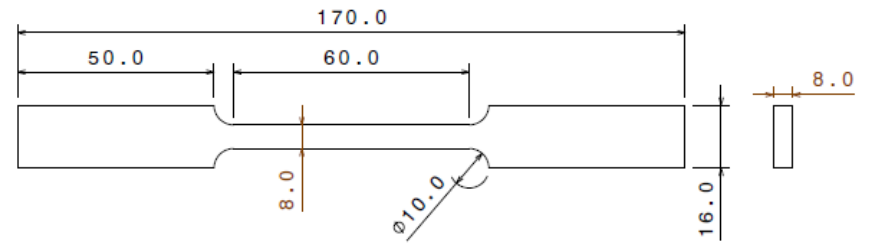

(a)

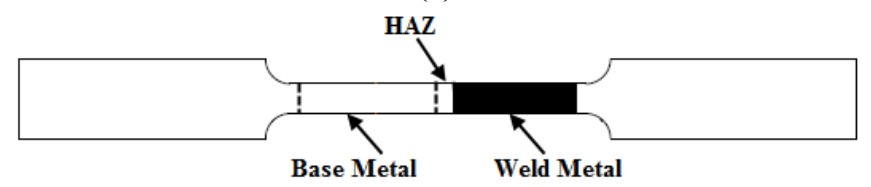

(b)

Fig. 1. Tensile test specimen (a) Geometry, all dimensions are in $\mathrm{mm}$ (b) schematic location of three welding regions within the gauge length [24] 


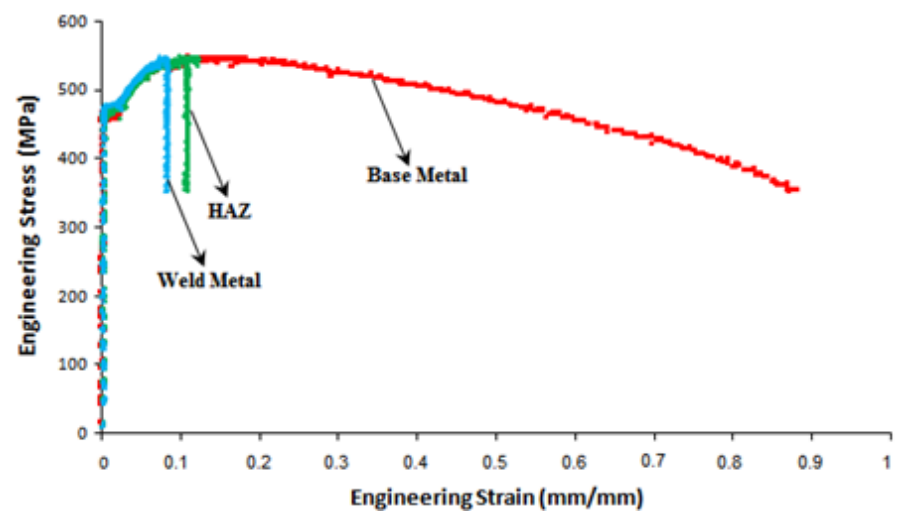

Fig. 2. Engineering stress-strain curves for S355G10+M at room temperature for different regions of weld section [24]

\subsection{Samples and Shot peening procedure}

Samples used in the current study included two welded specimens which were cut from an initial enormous welded plate with the thickness of $90 \mathrm{~mm}$. One of the specimens was in as-welded condition to consider the worst-case scenario with the highest local stress level around the weld toes, while the weld toes of the second specimen were ground flush in order to reduce the stress concentration near the welding zone. 43 passes of submerged arc welding (SAW) were utilized to join the initial double V-groove hot- rolled plates. This welding technique is extensively used for joining thick plates due to its high deposition rate and deep penetration [26, 27]. The welding process was performed in flat position $(1 \mathrm{G})$ using OP121TT flux and S3Si solid electrodes. The pre-heat and maximum inter-pass temperatures were chosen to be $60^{\circ} \mathrm{C}$ and $250^{\circ} \mathrm{C}$, respectively during welding process and no post-weld heat treatment (PWHT) was performed on the samples. General geometry of welded sample and the etched weld cross-section are depicted in Fig. 3. The geometry of the ground flush and the as-welded samples were the same.

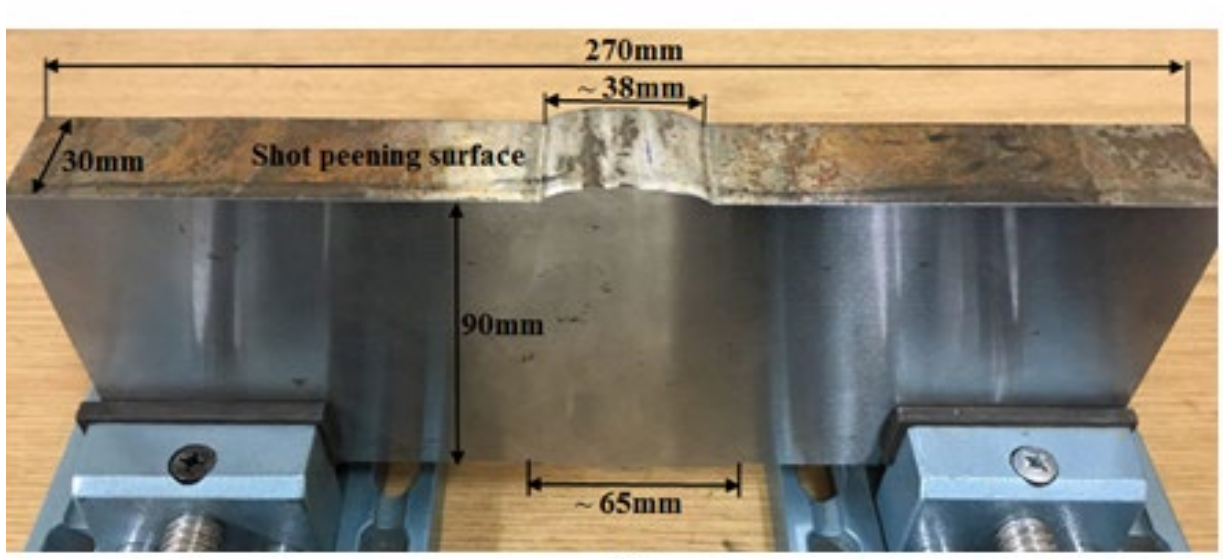

(a)

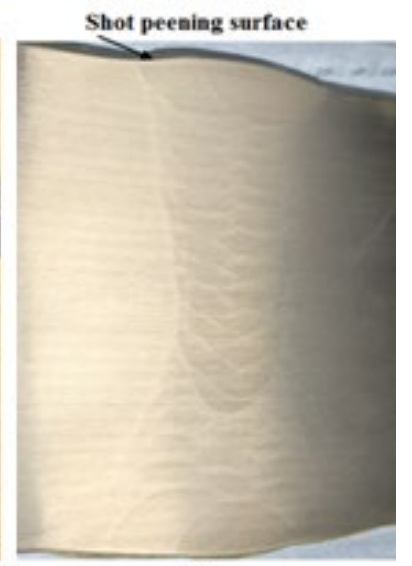

(b)

Fig. 3. (a) Welded specimen geometry (b) Cross-section of welded joint

After initial residual stress measurements, shot peening was performed on the top surface of both samples as this surface settles at the outer side of the monopile which is in tension, hence more critical. The entire top surface of the specimens was shot peened by S330 standard shots [28] 
using an air blast machine. Shot peening conditions are defined as follows: the surface peened twice in order to obtain the coverage of about $200 \%$ with the impingement angle of $90^{\circ}$ and $0.68 \mathrm{mmA}$ Almen intensity. Desired peening intensity was determined by directly measuring the arc height of a standard A-type Almen strip using an Almen gauge.

\subsection{Residual Stress Measurements}

Before and after shot peening process, through-thickness residual stress measurements of both samples were determined by measuring strains in $1.8 \mathrm{~mm}$ diameter holes using Incremental Centre Hole Drilling (ICHD) method and up to the depth of around 1.5 mm. FRS-2-11 TML strain gauge rosettes were used for these strain measurements. Experimental residual stress measurements were conducted on both the right and left-hand side of the weld bead and in an approximate distance of $4 \mathrm{~mm}$ from the weld toes. According to the weld bead geometry and the size of the strain gauges, this was the nearest position to the weld toes for mounting strain gauges. Total numbers of 6 and 5 measurements were performed on the as-welded and the weld + grind flush specimens, respectively. Fig. 4 illustrates residual stress measurement points in both specimens and one of the experimental measurements.

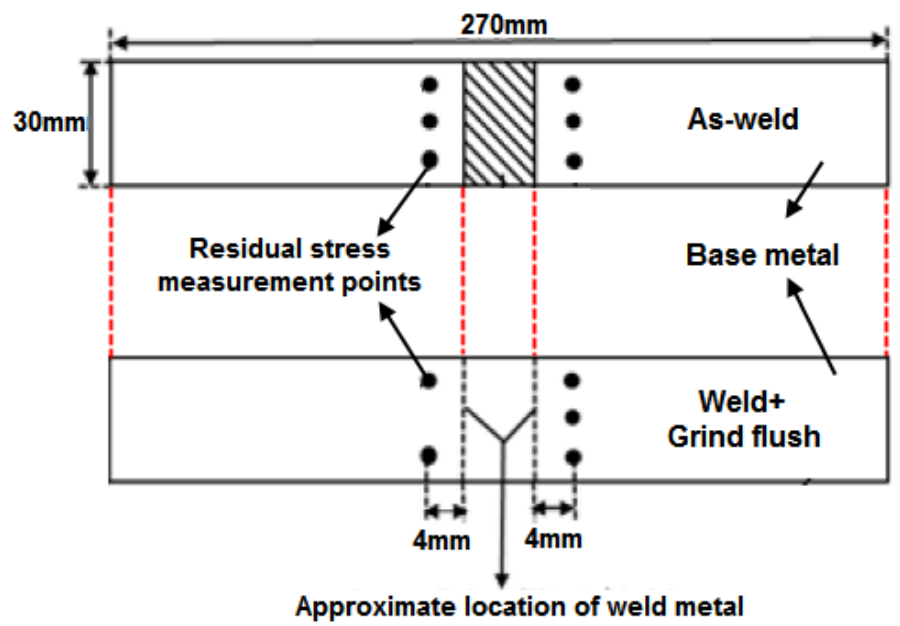

(a)

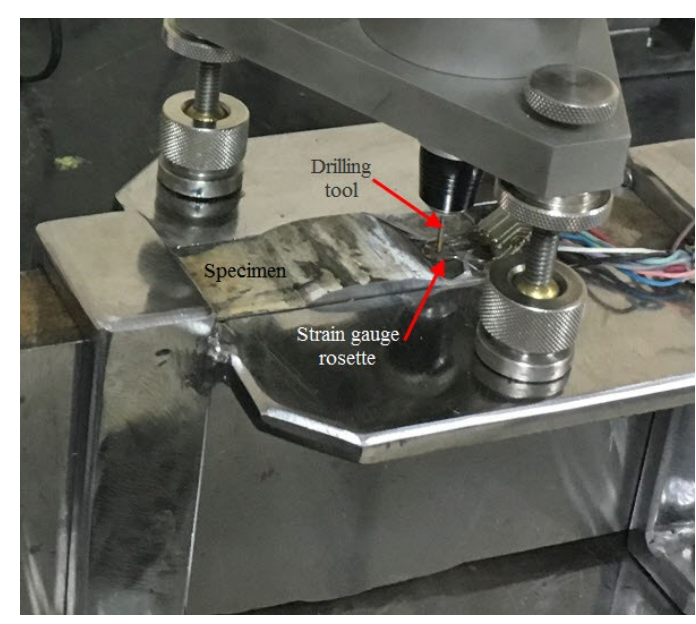

(b)

Fig. 4. (a) Residual stress measurement points in as-welded and weld + grind flush samples (b) An illustration of experimental residual stress measurements

\section{Numerical Analyses}

A set of 3D finite element models was developed to study the effect of welding model dimensions and the number of passes on predicting welding residual stresses as well as the effect of shot peening on redistribution of weld-induced residual stresses using commercial code ABAQUS 6.12.3 [29]. In welding simulations, element birth and death technique was applied in order to simulate the gradual weld metal deposition. Moreover, shot peening analyses were carried out using actual random distribution of shots which has the great potential of achieving full peening coverage $[21,22]$. In the present study, isotropic hardening model was used to describe the plastic behaviour of the welded sample and the shot peening target. 


\subsection{Welding Models}

\subsubsection{Simulation Strategies and Assumptions}

In the present study, uncoupled thermal-stress analyses were conducted to simulate welding process in which nodal temperatures are calculated in a distinct heat transfer analysis as a function of time and subsequently, they are read into the stress analysis [29]. In all welding thermal analyses used at the current study, Goldak's double ellipsoid model [30] was employed to simulate the volumetric moving heat source during welding process using DFLUX user subroutine [29]. This model which is among the most accurate and frequently used numerical heat source models [3133] could be defined as Eq. 1 in a fixed coordinate system.

$$
\mathrm{q}_{\mathrm{f}, \mathrm{r}}(\mathrm{x}, \mathrm{y}, \mathrm{z}, \mathrm{t})=\frac{6 \sqrt{3} \mathrm{f}_{\mathrm{f}, \mathrm{r}} \mathrm{Q}}{\mathrm{abc} c_{\mathrm{f}, \mathrm{r}} \pi \sqrt{\pi}} \mathrm{e}^{-3\left(\frac{\mathrm{x}^{2}}{\mathrm{a}^{2}}+\frac{\mathrm{y}^{2}}{\mathrm{~b}^{2}}+\frac{[\mathrm{z}-\mathrm{v}(\mathrm{t}-\tau)]^{2}}{\mathrm{c}_{\mathrm{f}, \mathrm{r}}^{2}}\right)}
$$

where $\mathrm{q}$ is the power density distribution in the front and rear quadrants of the ellipsoidal source, $\mathrm{a}, \mathrm{b}$ and $\mathrm{c}$ are the semi-axes of the ellipsoid in the direction of coordinate axes, $\mathrm{v}$ is the welding speed, $\tau$ is the time lag necessary to define the position of the heat source at time $t=0$ [32]. $\mathrm{f}_{\mathrm{f}}$ and $\mathrm{f}_{\mathrm{r}}$ which denote the fraction of heat deposited in the front and rear quadrants of the ellipsoid, respectively, obey $f_{f}+f_{r}=2[30]$, and finally, $Q$ is the power of the welding heat source that could be calculated from Eq. 2 for electric arc welding.

$$
\mathrm{Q}=\eta \mathrm{EI}
$$

where $\eta, E$ and $I$ are the arc efficiency, welding voltage and welding current, in turn. In finite element studies, the welding voltage and current of each weld passes were selected according to the welding procedure specification (WPS).

Extracting temperature history is the main purpose of the thermal analysis. Hence, sufficient recognition of the heat transfer methods which involve during the welding process and their related principles plays a vital role in this part of simulations. In the present study, all three types of heat transfer methods, including the conduction, convection and radiation were taken into account. The thermal conduction within the models body could be expressed according to the Fourier's law as Eq. 3.

$$
\overrightarrow{\mathrm{q}}=-\mathrm{k} \nabla \mathrm{T}
$$

where $\overrightarrow{\mathrm{q}}$ is heat flux density, $\mathrm{k}$ is the thermal conductivity and $\nabla \mathrm{T}$ is the temperature gradient. In the current investigations and according to [25,34], the thermal conductivity was increased artificially at the temperatures higher than the melting point to consider the fluid flow in the weld pool. The heat loss from the surfaces of the models through both radiation and convection was taken into consideration in welding simulations assuming the emissivity of $\varepsilon=0.8$ and the convective heat transfer coefficient of $\mathrm{h}=10 \mathrm{~W} / \mathrm{m}^{2 \circ} \mathrm{C}$ [25]. It is clear that heat losses due to radiation are more significant at high temperature areas locating in and near the weld zone, while at other regions with lower temperature the convective heat transfer is predominant [35, 36]. In this study, the heat transfer coefficients $h$ and $\varepsilon$ are assumed to be temperature-independent for 
simplicity. However, the variations of heat transfer surfaces resulting from the addition of new passes were considered in all simulations and as will be explained later, the bottom surface of the models was not considered as a convective or radiator surface. After the addition of each pass, the models were permitted to cool down to a temperature lower than the maximum inter-pass temperature and at the end of the welding process, the models cooled down to the room temperature.

After calculating temperature histories, these data were fed into the stress analysis to compute stress distribution. According to several literatures [37, 38], the anneal temperature property was used in order to simulate the effects of consecutive melting and re-solidification of material during welding process. In the present study, a single anneal temperature was employed in which in temperatures higher than a specified temperature, the equivalent plastic strain is set to zero and all materials hardening are removed. Stress analyses were performed using the same geometry and the same number of steps as thermal models. Appropriate boundary conditions applied to mechanical finite element models to prevent rigid body motions have been illustrated in Fig. 5

According to the mesh sensitivity analysis, $1 \times 1 \times 0.5 \mathrm{~mm}^{3}$ elements were employed in weld bead and its adjacent regions of the welding models. In order to reduce the computational costs, coarser elements were exploited in other regions. DC3D8 8-node linear heat transfer brick and C3D8R 8-node linear 3D-stress brick with reduced integration and hourglass control elements were used in welding thermal and stress analyses, respectively.

\subsubsection{Parametric Studies}

Since both samples which were used in the current study had been cut from another enormous welded section with lengthy weld beads, it was necessary to perform the finite element studies on larger models. However, having such large dimensions with the thickness of $90 \mathrm{~mm}$ and a large number of weld passes (43 passes) made it impossible or at least worthless to simulate the fusion welding process of the whole model with all its details due to the extremely high computational time. Thus, some finite element simulations were firstly conducted to study the effect of number of passes on predicting surface residual stresses distribution. This part of studies included three $160 \times 32 \times 54.77 \mathrm{~mm}^{3}$ models with 4,6 and 25 weld passes. Theses passes were selected from the outer weld groove which was the external surface and shot peened in reality. As in this case the bottom surfaces of the models are not the actual, external surfaces of the samples, they were not considered as a heat loss surface. All properties (e.g. the boundary conditions and the general dimensions) of the whole three models which were used in this part of numerical studies were the same, apart from the number of passes and their relative partitions. The geometry of the 6-passes model has been shown in Fig. 5. This model was used as "Reference Model" in the next part of the parametric studies.

The effect of finite element models dimensions on prediction of welding residual stress distribution was investigated by employing three models. According to the previous part of the study, all three models contained six weld passes and the same thickness of $54.77 \mathrm{~mm}$. Two of these models were used to study the effect of model dimensions in transverse direction with the dimensions of $32 \times$ 
used to investigate the dimensions effect in longitudinal direction. The results obtained from these models were later compared with the "Reference Model". To better comprehend, these models and their relationship with the "Reference Model" are schematically presented in Fig. 6. After analysing these results, the $96 \times 160 \mathrm{~mm}^{2}$ model was selected as the "Global" model for the rest of the simulations. It is worth mentioning that in all dimensions which expressed as "a×b" or "a, b", "a" and "b" represent the weld line length in longitudinal direction and the model's length in transverse direction, respectively.

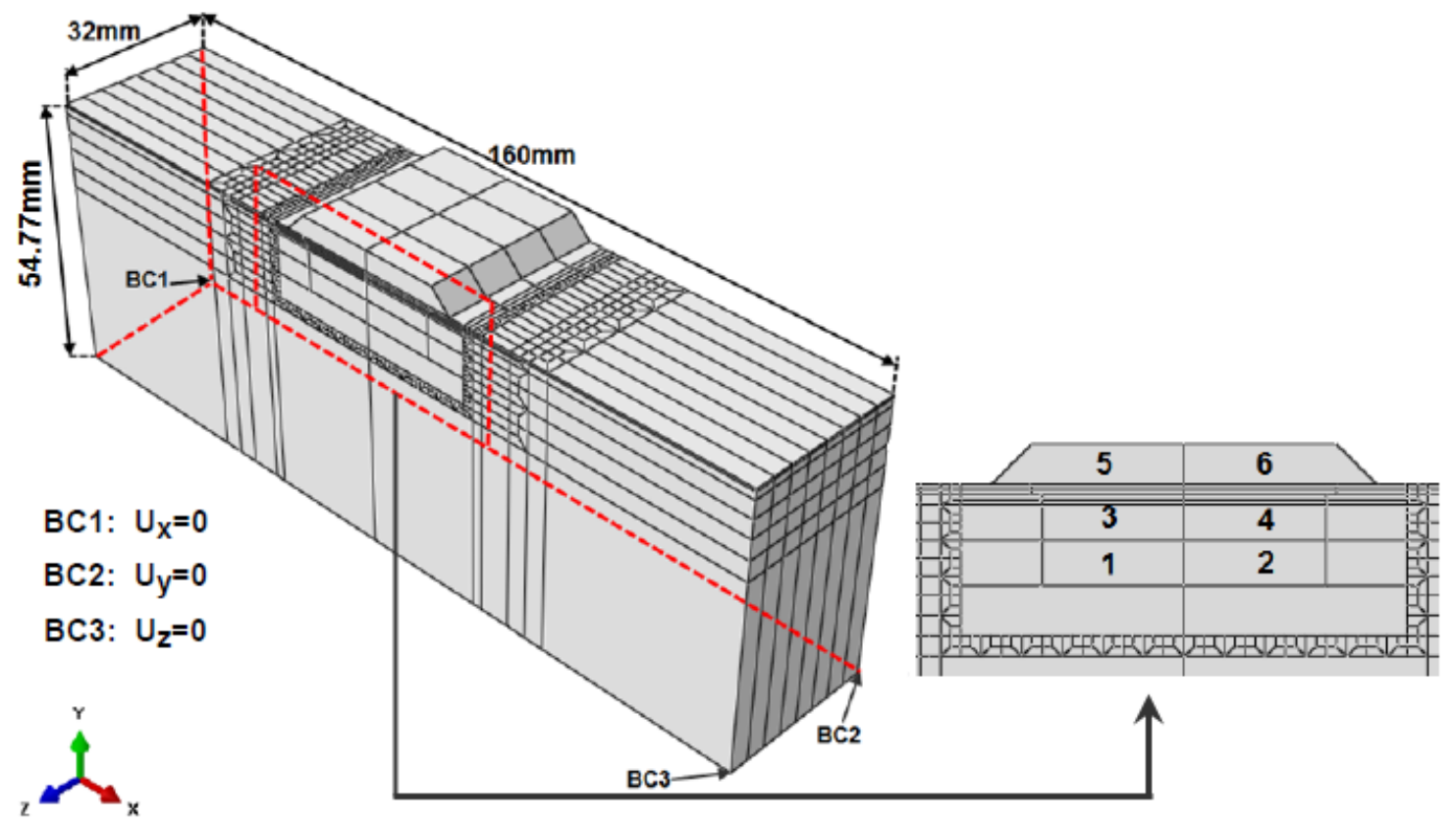

Fig. 5. General welding model dimensions, boundary conditions and pass sequences in 6 -passes model

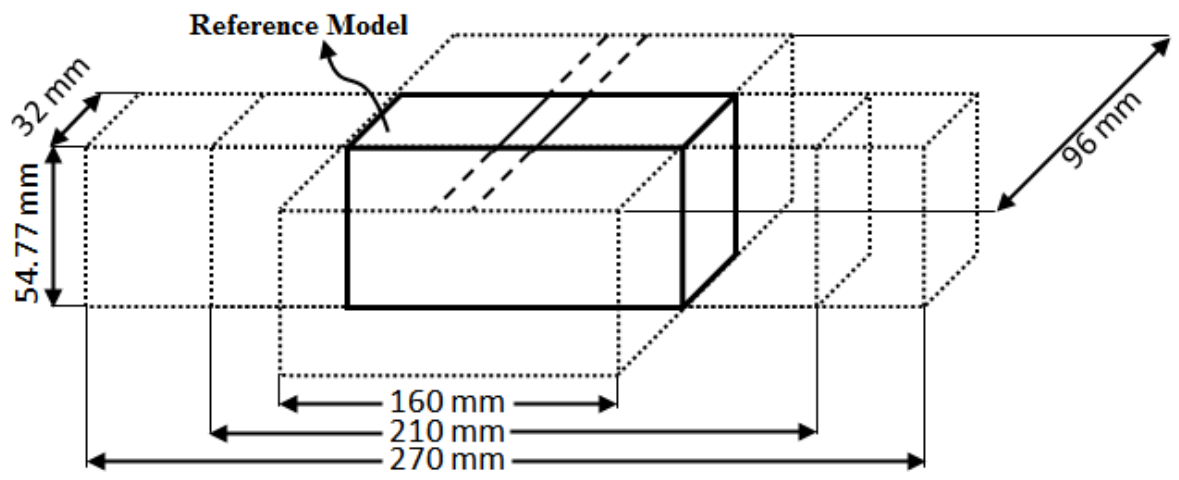

Fig. 6. Schematic illustration of the models used in welding model dimensions parametric studies

The last step of parametric studies was investigating the effect of cutting process on the residual stress distribution of the welded joint. Cutting process was simulated on the $96 \times 160 \mathrm{~mm}^{2}$ weld model in order to reach a thinner slice with the weld bead length of about $32 \mathrm{~mm}$. The simulation 
of the cutting process was performed by simply removing the elements in cutting area using the *MODEL CHANGE option in ABAQUS. Fig. 7 depicts the location of both cuttings.

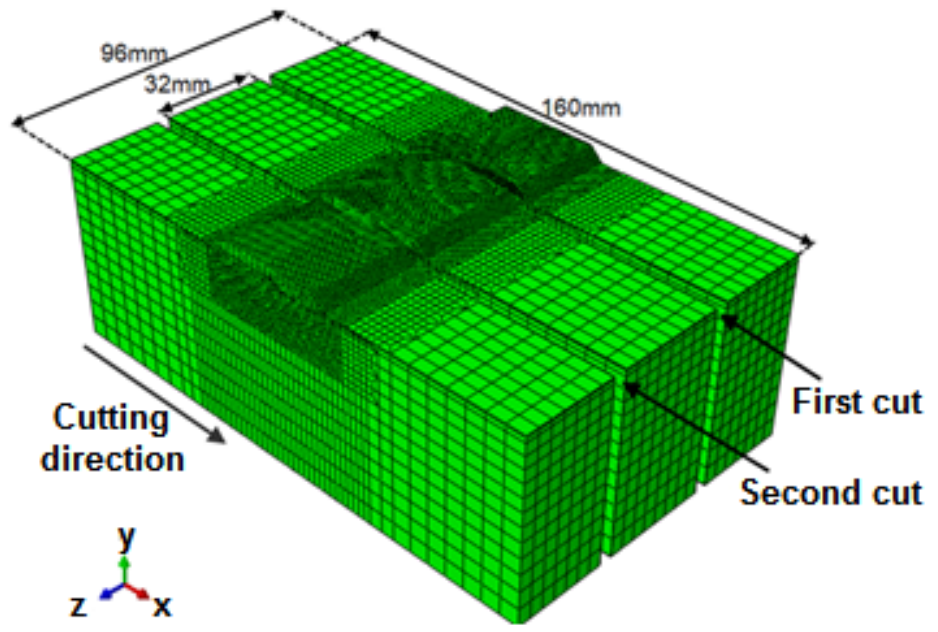

Fig. 7. The location of cuts in cutting simulation

\subsubsection{Welding Sub-Model}

Prior to shot peening simulations, a $6 \times 6 \times 3 \mathrm{~mm}^{3}$ welding node-based sub-model was developed with the aim of transferring residual stresses from the "Global" welding model to the smaller shot peening model with finer meshes. In this technique, the nodal result fields of the "Global" model (here including temperature and displacement degrees of freedom) are interpolated onto the submodel nodes [29]. Sub-model boundary conditions were applied on all exterior faces of the model except the top surface. Fig. 8 (a) and (b) illustrate the meshing of both welding global and submodel as well as the sub-model geometry.

\subsection{Shot Peening Simulations}

Shot peening models were developed with the same geometry as welding sub-model. All peening conditions including the coverage, incident angle and the shot size were exactly the same as experimental procedure. Moreover, the shots velocity was chosen to be about $65 \mathrm{~m} / \mathrm{s}$ to replicate the experimental Almen intensity. In these simulations, isotropic coulomb friction coefficient of 0.2 was utilized to define the contact behaviour between shots and the target surface[39]. Furthermore, the shots and the target were considered to behave as elastic and elastic-plastic materials, respectively. In addition, material damping was taken into account for the target part by employing Rayleigh damping model to ensure that residual oscillations are damped properly and do not affect the final results $[19,22,23]$. Rayleigh damping model could be expressed by Eq. 4 [29].

$$
\mathrm{C}=\alpha_{\mathrm{R}} \mathrm{M}+\beta_{\mathrm{R}} \mathrm{K}
$$

In which $C$ is the damping matrix, $M$ is the mass matrix, $K$ is the stiffness matrix, $\alpha_{R} \quad \beta_{R}$ are mass and stiffness proportional constants, in turn. In the present study, the value of $\beta_{\mathrm{R}}$ was set to zero according to $[22,23]$ and $\alpha_{R}$ was determined by trial and error. Prior to multi-impact shot 
peening model, an axi-symmetric and a single impact model had been developed with the aim of evaluating $\alpha_{R}$ and the indentation radius ( $r$ ) of each impact, respectively. The minimum number of shots and their random positions to achieve the favourable shot peening coverage were then calculated by a code written in Python programming language on the basis of the single indent and the peening area radius (C). In the multi-impact model, the peening area with the radius of $\mathrm{C}=0.5 \mathrm{~mm}$ was peened by 63 shots in order to obtain the coverage of $200 \%$. This value is slightly greater than $\mathrm{C}=4 \mathrm{r}$, the minimum size of the treated surface that does not affect the shot peening induced residual stress distribution in finite element studies [39].

In all shot peening models, the elements of the impact area were selected to be $0.02 \times 0.02 \times 0.02$ $\mathrm{mm}^{3}$ regarding the mesh convergence study and the bottom surface of the target part was entirely fixed and prevented from any displacements and rotations in all directions. Fig. 8(d) shows the shots random arrangements in the FE model.

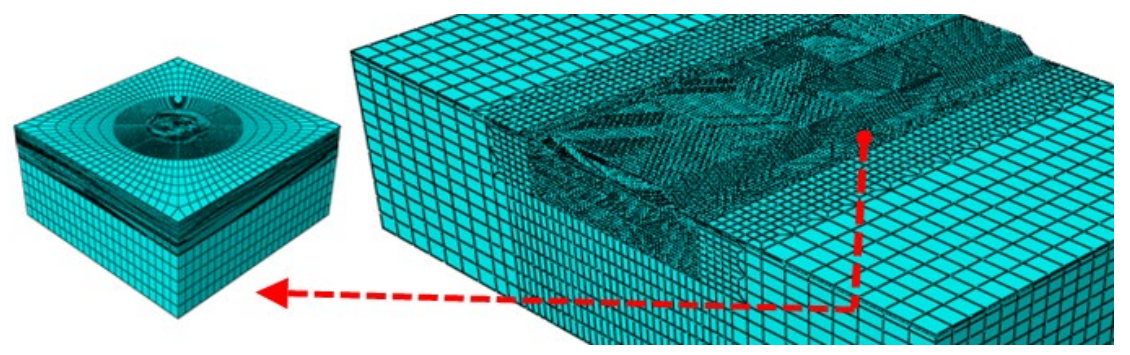

(a)
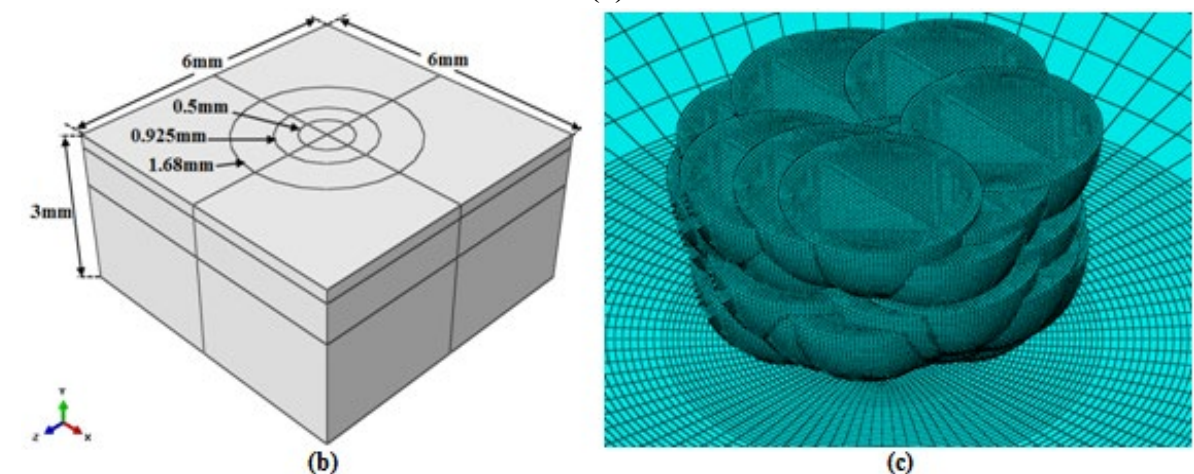

Fig. 8. (a) Meshing of the welding global and sub-model (b) The geometry of the sub-model (c) shots random arrangements

\section{Results and Discussion}

\subsection{Welding Parametric Studies}

All the results of this study are presented and discussed in this section. Numerical results of studying the effect of number of weld passes on predicting through-thickness residual stresses distribution are depicted in Fig. 9. These results were extracted from the same through-thickness paths as the locations of experimental measurements and on equal distances from the weld toe in whole three models. Overall, what stands out from the Fig. 9 is that the residual stresses distribution in 25, 6, and 4-passes models exhibit entirely different values in the models depth. However, a more-detailed look at the near surface regions of the charts which are magnified in 
Fig. 10 reveals that both the transverse and longitudinal components of residual stresses are almost the same for 25 and 6-passes models. This meant that for the present thick, welded samples with a large number of passes, only simulating few near surface passes could represent a very good estimation of the residual stresses distribution of these regions.

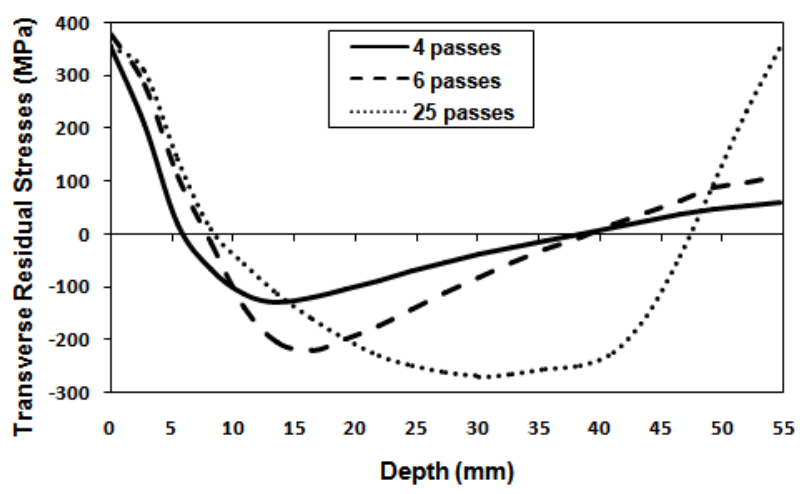

(a)

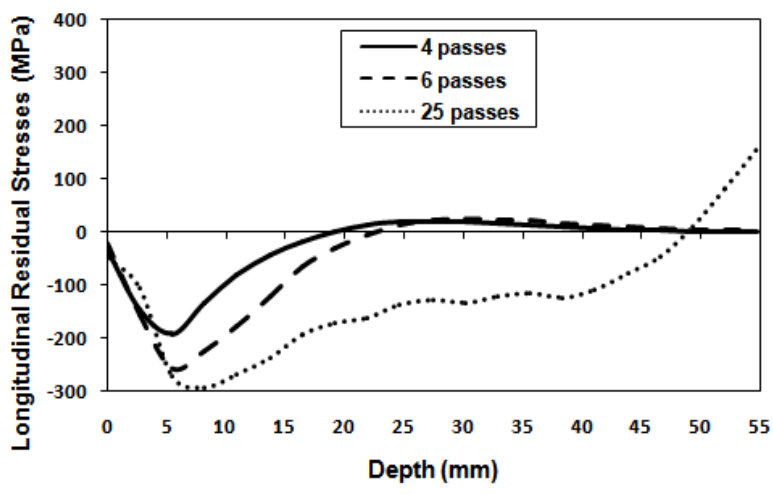

(b)

Fig. 9. Through-thickness residual stresses distribution in 25, 6 and 4-passes models (a) Transverse stresses

(b) Longitudinal stresses

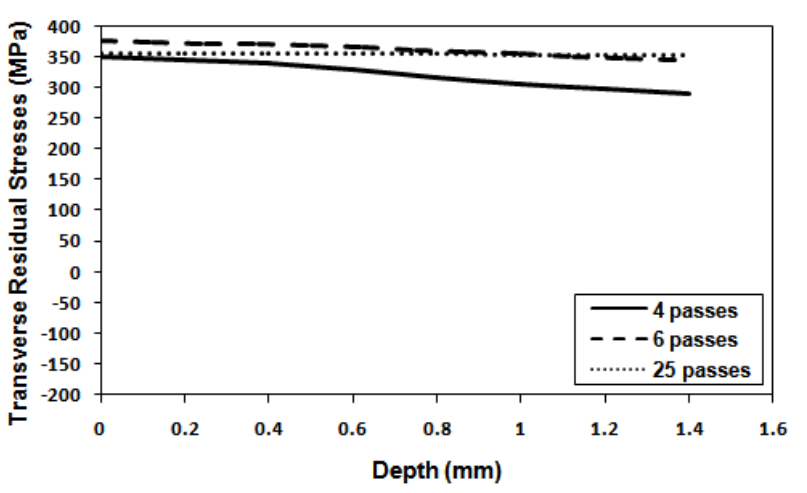

(a)

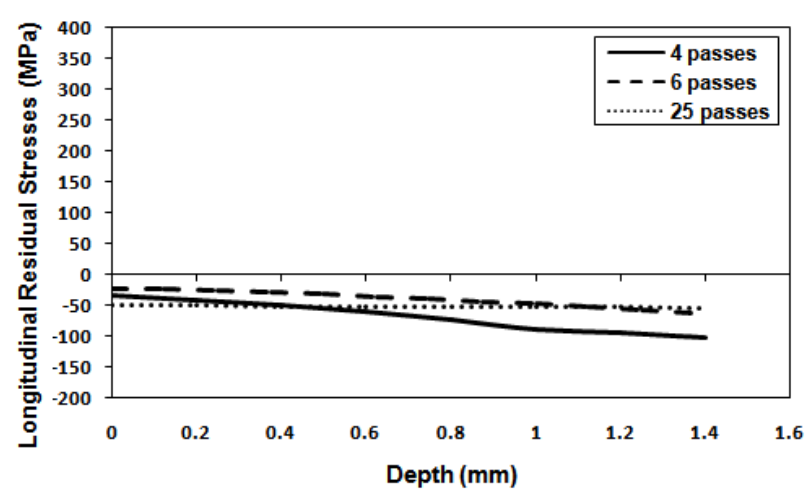

(b)

Fig. 10. Near surface residual stresses distribution in 25, 6 and 4-passes models (a) Transverse stresses (b) Longitudinal stresses

The little effect of the number of passes on anticipating welding surface residual stresses could be explained by the interactions between different passes in multi-pass welding. In multi-pass welding process, the thermal stresses and the heat remains in the body as a consequence of adding the previous passes on the one hand, and the material reheating or probably remelting of some parts of the previous passes due to running the new passes on the other hand, results in a complex residual stresses distribution which is different from welding induced residual stresses in a singlepass joint. However, it is clear that getting away from each pass, the interaction between that pass and the recently added passes decreases gradually. One the basis of this explanation, it could be concluded that in large, thick multi-pass sections, the effect of the underlying, firstly added passes on the near surface residual stresses distribution is negligible. 
Fig. 11- 13 illustrate the transverse and longitudinal components of welding residual stresses along three distinct paths obtained from dimensional parametric studies.

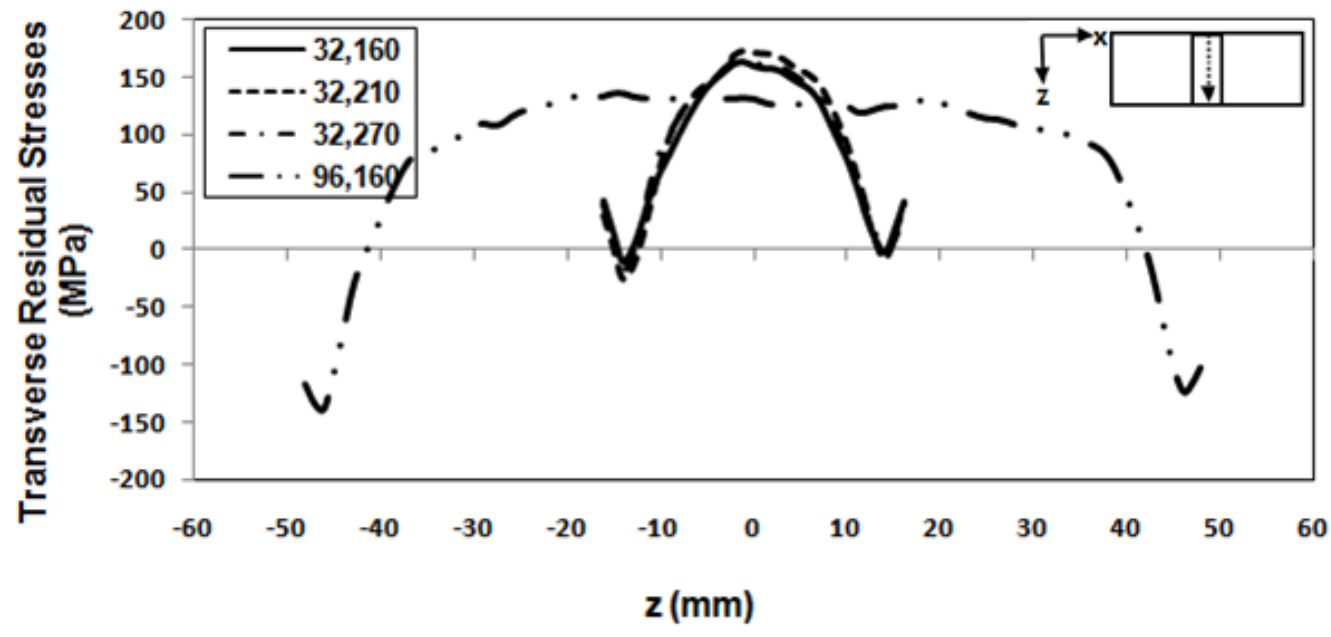

(a)

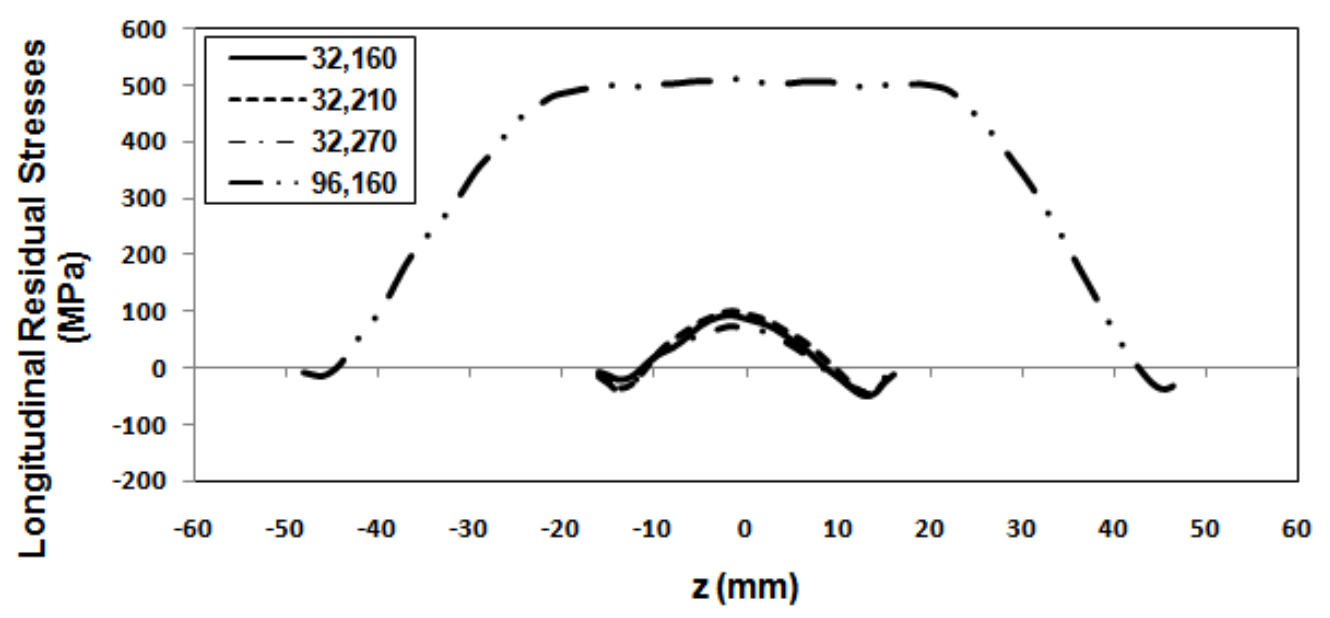

(b)

Fig. 11. The effect of models' dimensions on predicting welding residual stresses along weld centreline (a) Transverse stresses (b) Longitudinal stresses 


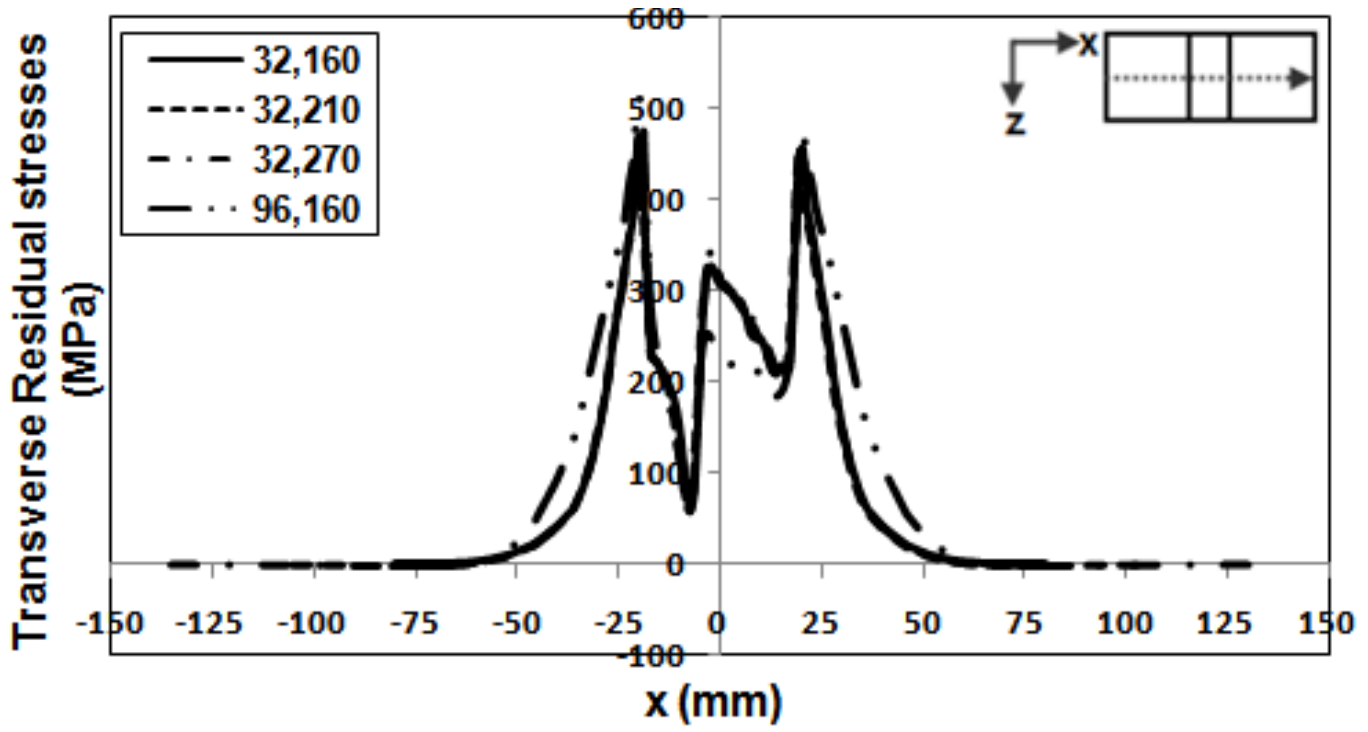

(a)

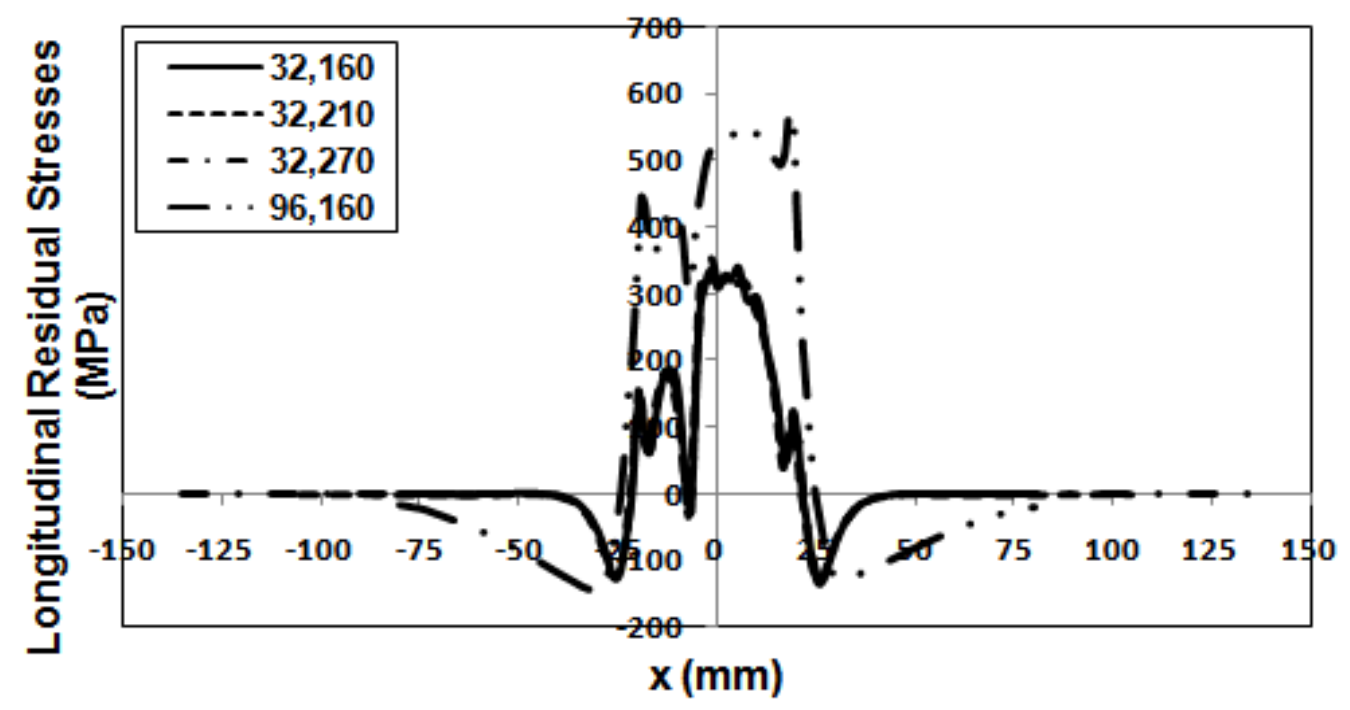

(b)

Fig. 12. The effect of models' dimensions on predicting welding residual stresses along transverse direction (a) Transverse stresses (b) Longitudinal stresses 


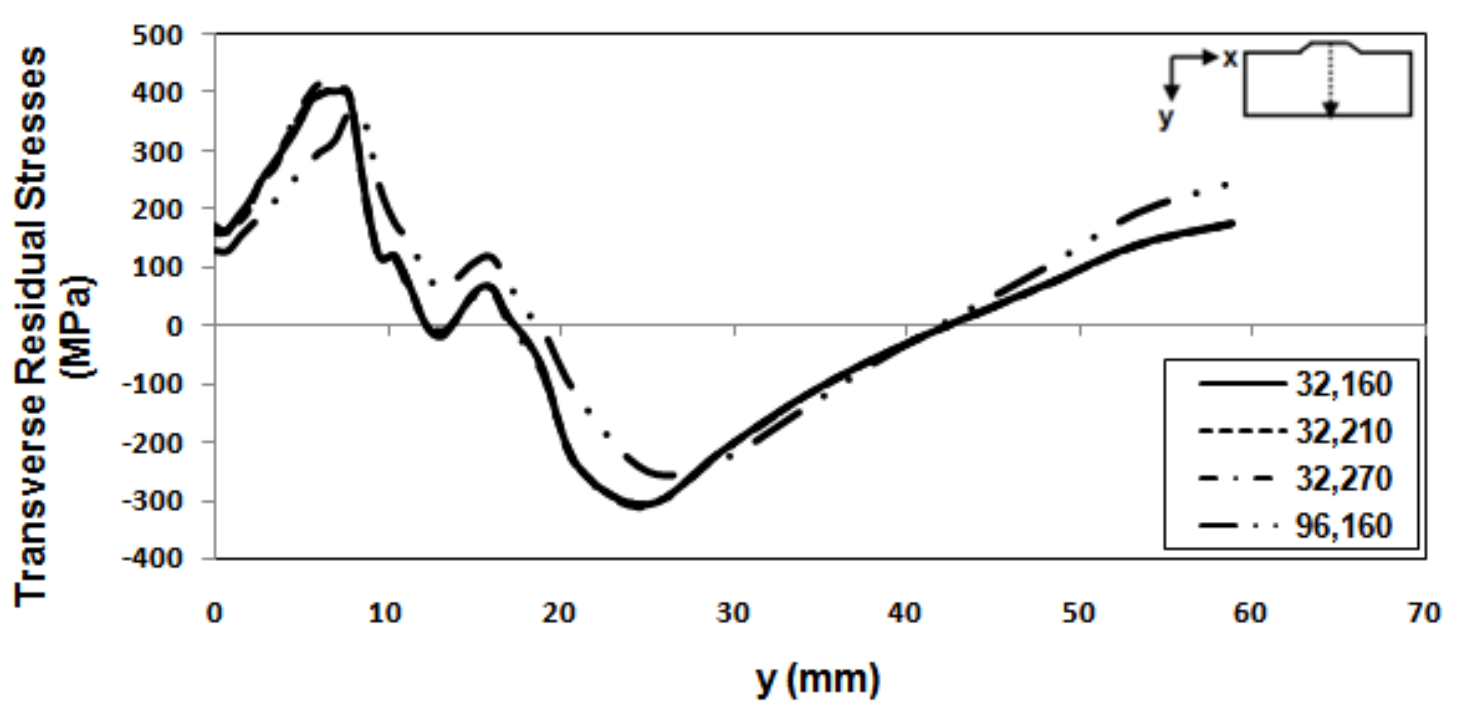

(a)

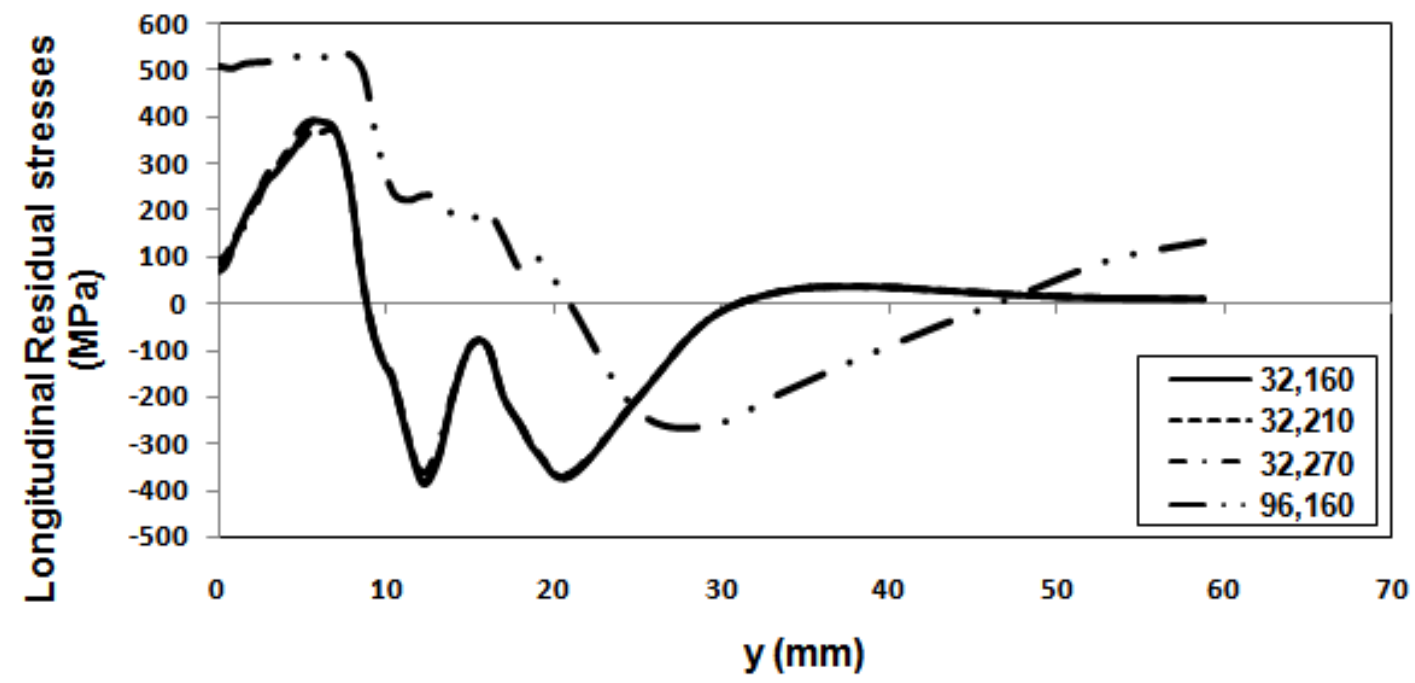

(b)

Fig. 13. The effect of models' dimensions on predicting welding residual stresses through depth (a) Transverse stresses (b) Longitudinal stresses

According to Fig. 11-13, changing models length in transverse direction (the direction perpendicular to weld line) had a negligible effect on predicting both the longitudinal and transverse welding residual stresses. By contrast, dramatic changes could be observed in predicted residual stresses as a consequence of changing models dimensions in longitudinal direction (the direction parallel to weld line). However, it is obvious that in this case, the sensitivity of the longitudinal component of welding residual stresses is more than the transverse component as tripling the longitudinal dimension from $32 \mathrm{~mm}$ to $96 \mathrm{~mm}$, created $400-600 \%$ error in predicting 
longitudinal stresses, while the highest error in predicted transverse stresses was only $19 \%$ in comparison with the "Reference Model". Beside, this marginal error in predicting transverse stresses was only restricted to the weld central point $(z=x=0)$ and getting away from this point in both longitudinal and transverse direction, the error rapidly reduced.

The significant difference between the longitudinal and transverse components of welding residual stresses as a result of lengthening the weld bead could be interpreted by the nature of welding process and the mechanisms govern the residual stresses formation in this process. During fusion welding, the manner of receiving heat from the moving heat source at the beginning and the end points of the weld line are dissimilar from the middle area in terms of the heat duration and magnitude. As a result of these circumstances, the temperature history at these regions is different from the rest of the weld line, and the outcome is a different residual stresses distribution within these areas. In other words, it could be said that the beginning and the end regions of the weld line contain a "Transient" residual stresses distribution, while getting far enough away from these areas the temperature history and consequently the residual stresses distribution become stable and constant. This could be clearly observed in Fig. 11 for the $96 \times 160 \mathrm{~mm}^{2}$ model. According to the high energy input used for submerged arc welding, it seems that the transient stresses distribution length could be relatively large at both sides of the weld line. Thus, with the same welding parameters in experiments and numerical studies (such as the welding speed, heat input, etc), shortening the weld bead in simulations could results in considerable errors in prediction of residual stresses (particularly the longitudinal component) compared to the real longer weld bead, since in this case, the weld line finishes before the temperature history and the resulting stresses distribution pass the transient conditions and reach their stable values. The exception is the case that the shortened weld line length is enough longer than the transient length. However, it should be noted that further investigations are necessarily needed to ensure the integrity of the recent conclusion.

Redistribution of welding residual stresses due to the cutting process is shown in Fig. 14. Looking at the Fig. 14, it could be seen that releasing some stresses, the cutting process lowered the level of welding induced residual stresses. This meant that the effect of the cutting process and lengthening the model dimension in longitudinal direction had inverse effect on the magnitude of welding residual stresses, as increasing the weld length increases the level of residual stresses, while the cutting process decreases them. Putting all these together and since the welded specimens used in the current study had been cut from another giant welded plate and simulating such huge welding model was not viable due to the extremely high computational time, the $96 \times 160 \mathrm{~mm}^{2}$ without any cutting could be supposed to contain the same residual stresses distribution as the real samples which used in experimental parts of the study with the weld bead length of about $30 \mathrm{~mm}$. Thus, in the present study, the $96 \times 160 \mathrm{~mm}^{2}$ model with 6 weld passes was selected as the finite element model for subsequent comparisons. It should be again noted that cutting simulations were done without considering any specific details. 


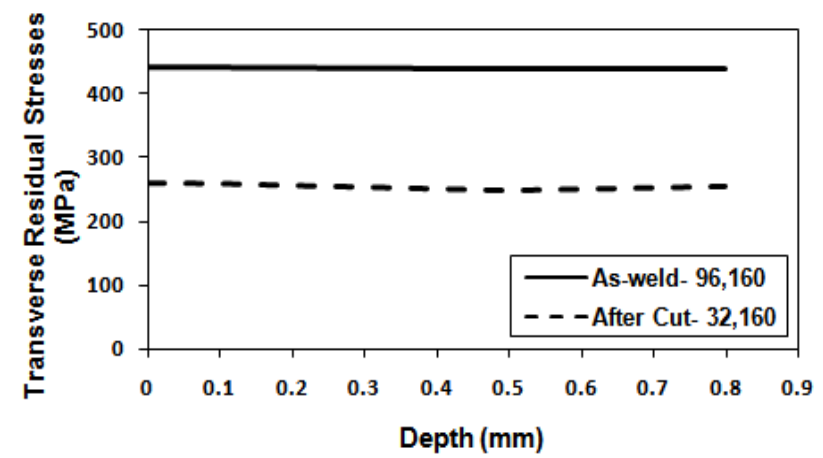

(a)

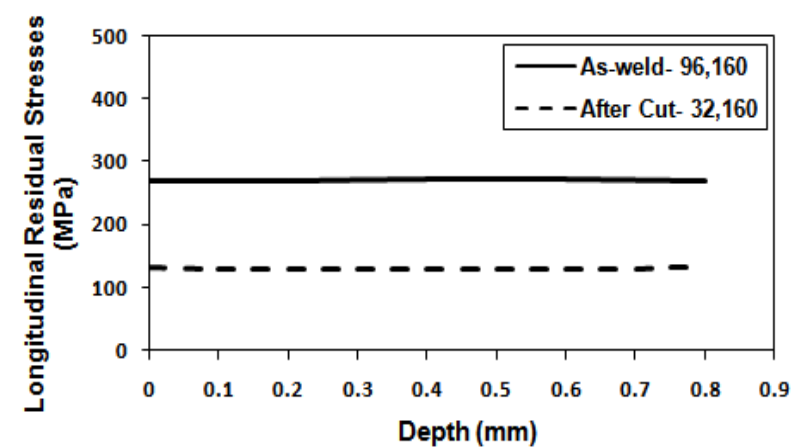

(b)

Fig. 14. The effect of cutting on residtribution of welding residual stresses (a) transvrse stresses (b) Longitudinal stresses

\subsection{Welding, Flush Grinding and Shot Peening}

Near surface residual stresses distributions of the as-welded sample obtained from the numerical analyses and ICHD measurements before and after shot peening are compared in Fig. 15. The abbreviations (Weld), (SP), (EXP) and (FE) in all figures stand for the as-welded condition, shot peening process, experimental and finite element results, in turn. According to Fig. 15, both the experimental and numerical results before and after shot peening are in good agreement. The given results reveal that despite existing considerable amounts of tensile residual stresses in the aswelded sample in both transverse and longitudinal directions, shot peening withdrew these stresses effectively and introduced a significant amount of compressive residual stresses up to around 0.3 $\mathrm{mm}$ through the thickness. Even up to the depth of around $0.7 \mathrm{~mm}$, the magnitude of the tensile residual stresses after shot peening were still lower than the as-welded tensile stresses. However, the effect of shot peening induced residual stresses gradually declined by moving through the thickness and the residual stresses again reached the tensile as-welded stresses in approximate depth of about $1 \mathrm{~mm}$. Quantitative comparisons of welding results demonstrate that unlike the experimental measurements, the FE model could only predict the magnitude of welding residual stresses at the beginning and the end of the measuring span and could not anticipate the throughspan residual stresses variations. High computational costs and hardware limitations on employing more through-thickness elements in welding FE models are some of the resources of this error. Simplifications and the sensitivity of welding simulations to material properties and welding procedure's details which were not precisely available are the other reasons of errors. Also, the small differences between numerical and experimental after shot peening results are likely due to the fact that material properties are strongly affected by welding process which has not been considered in shot peening simulations. An example of this effect could be observed in Fig. 2. 


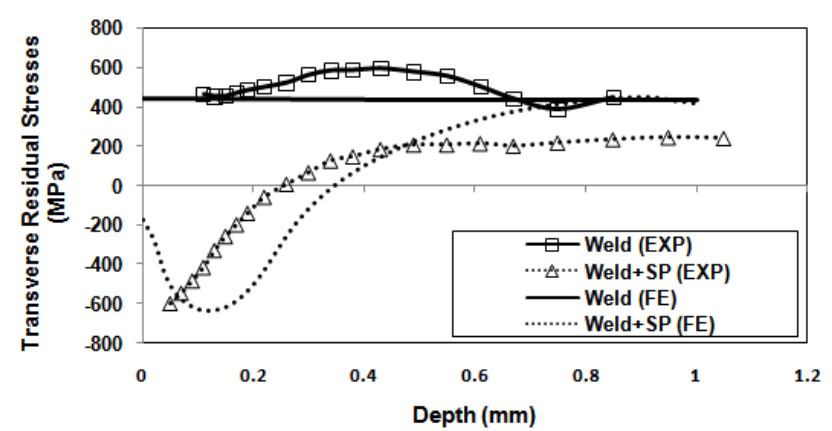

(a)

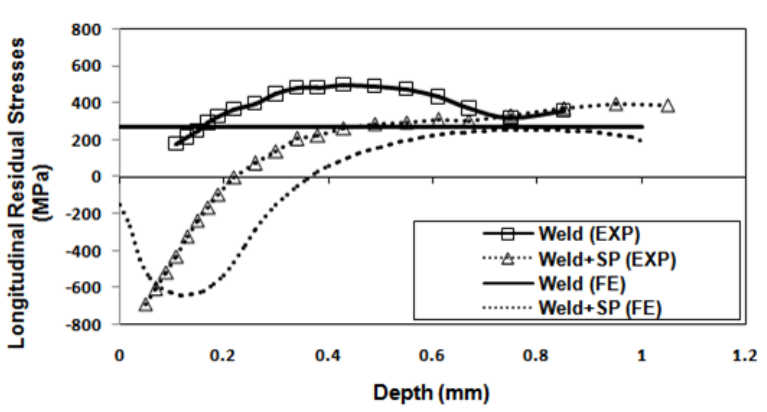

(b)

Fig. 15. Experimental and finite element results of the as-welded sample before and after shot peening (a) Transverse stresses (b) Longitudinal stresses

The beneficial effect of shot peening on redistribution of multi-pass welding residual stresses is also depicted graphically in Fig. 16. This figure shows the contour of residual stresses components in half of the shot peening model prior to shot peening, after the first impact and after all shots peened the surface. Converting the welding tensile stresses (with negative signs) to compressive ones (with positive signs) through the impact zone could be clearly observed in this figure.

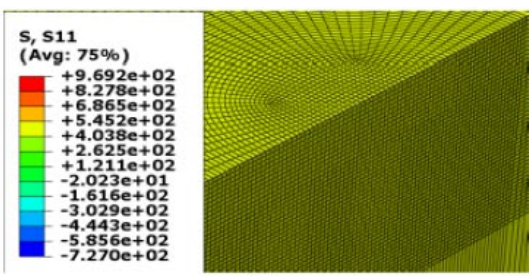

(a)

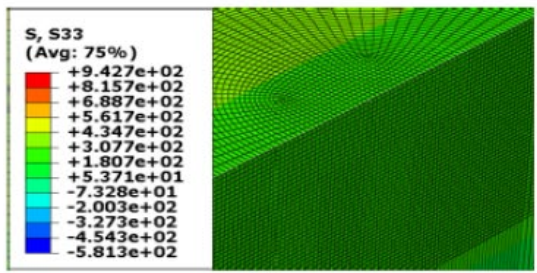

(d)
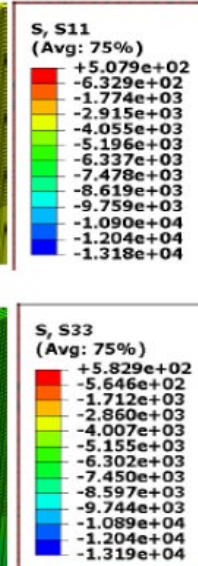

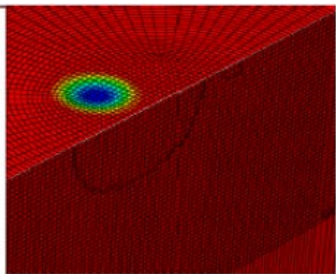

(b)

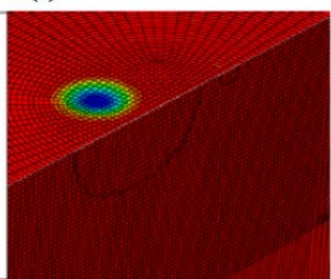

(e)
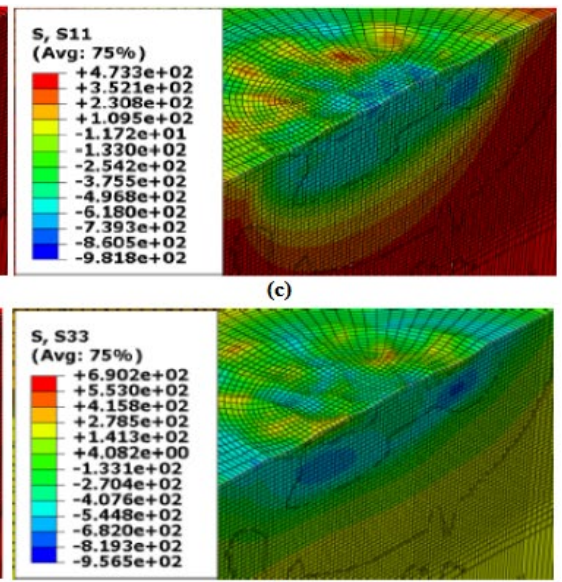

(f)

Fig. 16. Residual stresses contours for half of the shot peening model. The first and the second rows illustrate the transverse and longitudinal stresses, respectively. (a),(d) The as weld condition (b),(e) After the first impact (c),(f) After all impacts

The effect of shot peening on redistribution of residual stresses of the ground flush sample (weld + grind flush) is demonstrated in Fig. 17. As no further information was available about the flush grinding parameters and its conditions, the ground flush sample related results were only obtained from the experimental procedures. In all figures, the (GF) abbreviation on the chart legend stands for the ground flush process. According to Fig. 17, despite the high level of tensile residual stresses existed in the ground flush sample, after shot peening, compressive residual stresses with a maximum magnitude of around $400 \mathrm{MPa}$ were developed in it up to the depth of $0.23 \mathrm{~mm}$. This 
meant that shot peening had the beneficial effects with the same trend as the as-welded sample on the weld + grind flush specimen, too.

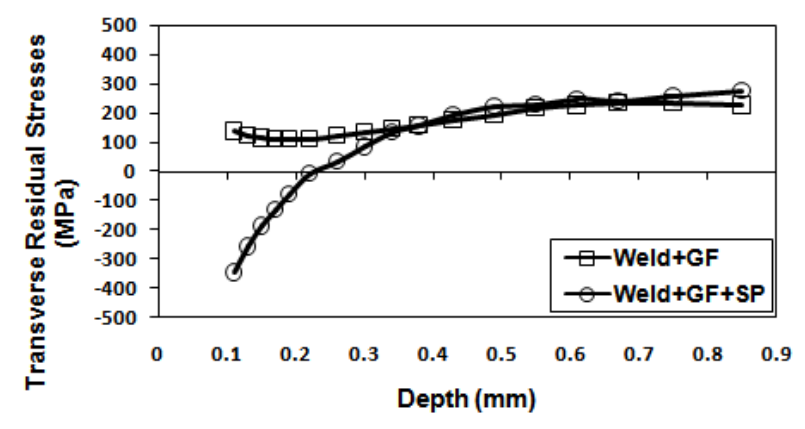

(a)

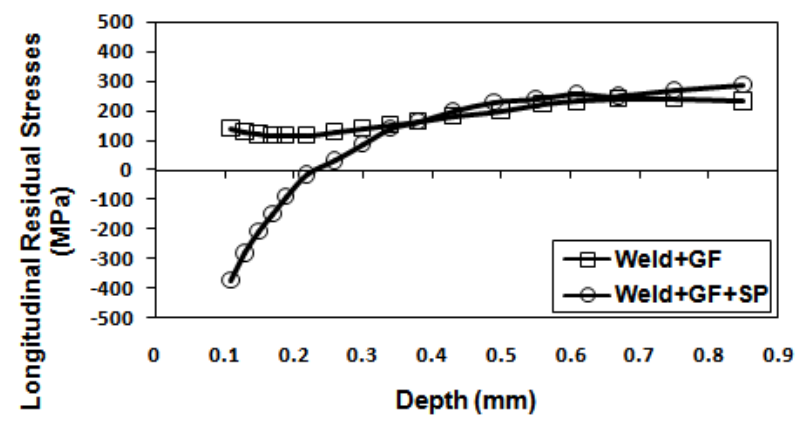

(b)

Fig. 17 . Experimental results of the ground flush sample before and after shot peening (a) Transverse stresses (b) Longitudinal stresses

In order to make more detailed comparisons between the as-welded and weld + grind flush samples before and after shot peening, the residual stresses components of all these cases are illustrate in Fig. 18. From this figure, it could be seen that although a high level of tensile residual stresses were presented in both the as-welded and the weld + grind flush specimens, grinding the weld beads significantly diminished the magnitude of residual stresses as it could be observed that in this case, the transverse component of residual stresses shows over 50\% reduction in ground sample compared to the as-welded one up to around $0.7 \mathrm{~mm}$ depth. The other striking point from Fig. 18 is that despite existing higher levels of tensile stresses in the as-welded sample, the maximum magnitude of compressive residual stresses induced by shot peening was also produced in this sample. Furthermore, the same depth of compressive stresses was achieved in both specimens after shot peening.

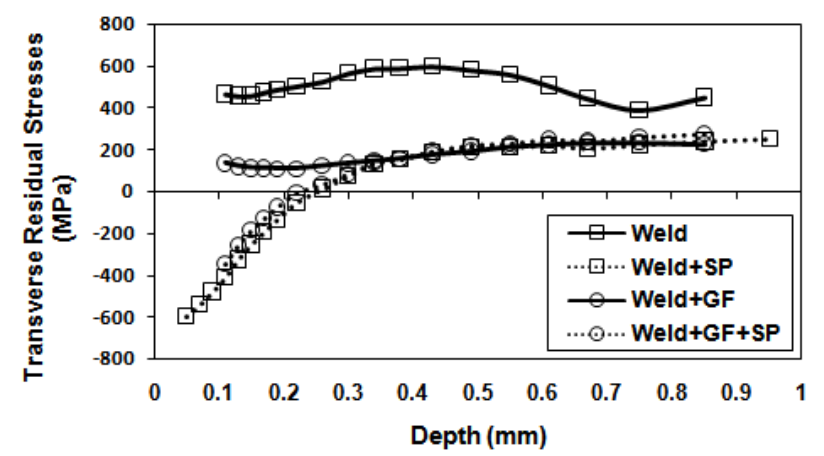

(a)

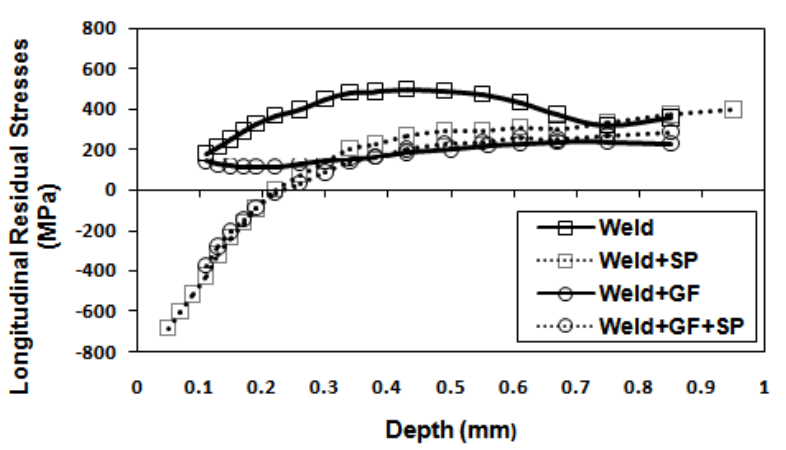

(b)

Fig. 18. Experimental results of both samples before and after shot peening (a) Transverse stresses (b) Longitudinal stresses

Another set of results are also depicted in Fig. 19. The aim of presenting this figure is to compare the level of in-depth transverse and longitudinal components of residual stresses before and after shot peening. A brief look at Fig. 19 (a) reveals that flush grinding of the weld beads converted the different welding residual stresses distributions (transverse and longitudinal 
components) to an equi-biaxial distribution. In addition to this, due to the nature of shot peening process which inherently introduces the equi-biaxial residual stresses distributions in the absence of initial stresses, the distribution of residual stresses in the ground flush sample remained equibiaxial after shot peening (Fig. 19 (b)). Finally, apart from the considerable dissimilarities in residual stresses distributions of the as-welded and the weld + grind flush samples, the redistribution of residual stresses in both samples were almost the same after shot peening (Fig. 19 (b)).

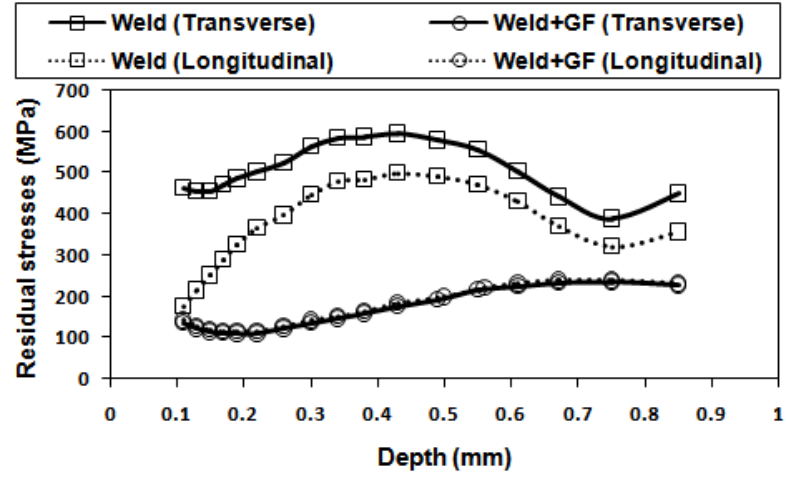

(a)

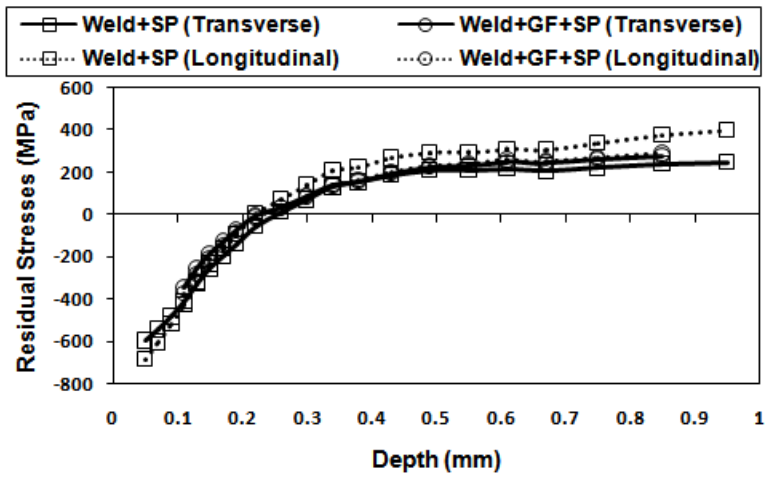

(b)

Fig. 19. Experimental transverse and longitudinal components of residual stresses in both samples (a) Before shot peening (b) After shot peening

\section{Conclusions}

In this study, the effect of shot peening on redistribution of residual stresses introduced by multipass submerged arc welding was numerically and experimentally investigated. Our findings can be summarized and concluded as follows:

- For enormous samples which contain a large number of weld passes, only simulating the few passes located near the surface could result in the prediction of "near surface" residual stresses with high accuracy.

- The reduction of pass numbers in FE modelling is not allowed to predict the whole throughthickness residual stresses distribution.

- Changing FE models dimensions in direction parallel with the weld passes (longitudinal direction) dramatically affected the residual stresses distribution, particularly the longitudinal stress components.

- Changing FE models dimensions in direction perpendicular to the weld passes (transverse direction) did not affect the residual stresses distribution, in the present study.

- The residual stresses distribution predicted by FE models were in good correlation with experimental ICHD measurements in both cases before and after shot peening for the aswelded specimen. 
- Even in huge welded structures with a large number of weld passes and high levels of tensile residual stresses, shot peening is remarkably profitable by introducing favourable compressive stresses on and near the surface.

- Applying the shot peening process on the weld + grind flush specimen resulted in a lucrative outcome as the as-welded specimen.

- Grind flushing the weld beads could itself lessen the level of welding residual stresses and introducing the equi-biaxial stresses in welded samples.

- Shot peening process could be effectively used as a simple, practical method for treating the multi-pass welding induced residual stresses in offshore wind turbine monopiles. However, as these structures are installed in extreme environments, evaluating the surface roughness and hardness before and after shot peening is also proposed.

\section{Acknowledgements}

The financial support from Bu-Ali Sina University under the grant number ... and the Cranfield University are greatly acknowledged.

\section{References}

1. Jung, S., S.-R. Kim, and A. Patil, Effect of monopile foundation modeling on the structural response of a 5MW offshore wind turbine tower. Ocean Engineering, 2015. 109: p. 479-488.

2. Velarde, J., Design of monopile foundations to support the DTU 10 MW offshore wind turbine. 2016, NTNU.

3. Mehmanparast, A., F. Brennan, and I. Tavares, Fatigue crack growth rates for offshore wind monopile weldments in air and seawater: SLIC inter-laboratory test results. Materials \& Design, 2017. 114: p. 494504.

4. Hensel, J., et al., Welding residual stresses as needed for the prediction of fatigue crack propagation and fatigue strength. Engineering Fracture Mechanics, 2018. 198: p. 123-141.

5. Radaj, D., Heat effects of welding temperature field, residual stress, distortion, 1992. Springer-Verlag, Berlin.

6. Paradowska, A., et al., Stress relieving and its effect on life of welded tubular joints. Engineering Failure Analysis, 2010. 17(1): p. 320-327.

7. Zhao, X., et al., Simulation of vibration stress relief after welding based on FEM. Acta Metallurgica Sinica, 2008. 21(4): p. 289-294.

8. Chen, X., et al., Investigation of microstructures and residual stresses in laser peened Incoloy $800 H$ weldments. Optics \& Laser Technology, 2014. 57: p. 159-164.

9. Bellow, D., M. Wahab, and M. Faulkner, Residual stresses and fatigue of surface treated welded specimens. Pergamon Press, Advances in Surface Treatments. Technology--Applications--Effects., 1986. 2: p. 85-94.

10. Bertini, L., V. Fontanari, and G. Straffelini, Influence of post weld treatments on the fatigue behaviour of Alalloy welded joints. International journal of fatigue, 1998. 20(10): p. 749-755.

11. Li, D., H. Chen, and H. Xu, Comparative responses of welded joints to surface mechanical attrition treatment and shot peening. Surface Engineering, 2009. 25(1): p. 15-20.

12. Molzen, M.S. and D. Hornbach, Evaluation of welding residual stress levels through shot peening and heat treating. SAE transactions, 2000: p. 140-146.

13. Sidhom, N., et al., Fatigue strength improvement of $5083 \mathrm{H} 11$ Al-alloy T-welded joints by shot peening: experimental characterization and predictive approach. International journal of fatigue, 2005. 27(7): p. 729745.

14. Gan, J., et al., The effect of shot peening on fatigue life of Q345D T-welded joint. Journal of Constructional Steel Research, 2016. 126: p. 74-82.

15. Dieng, L., et al., Parametric study of the finite element modeling of shot peening on welded joints. Journal of Constructional Steel Research, 2017. 130: p. 234-247. 
16. Mori, K.-i., K. Osakada, and N. Matsuoka, Finite element analysis of peening process with plasticity deforming shot. Journal of materials processing technology, 1994. 45(1-4): p. 607-612.

17. Meguid, S., et al., Three-dimensional dynamic finite element analysis of shot-peening induced residual stresses. Finite elements in analysis and design, 1999. 31(3): p. 179-191.

18. Guagliano, M., Relating Almen intensity to residual stresses induced by shot peening: a numerical approach. Journal of Materials Processing Technology, 2001. 110(3): p. 277-286.

19. Meguid, S., G. Shagal, and J. Stranart, 3D FE analysis of peening of strain-rate sensitive materials using multiple impingement model. International Journal of Impact Engineering, 2002. 27(2): p. 119-134.

20. Majzoobi, G., R. Azizi, and A.A. Nia, A three-dimensional simulation of shot peening process using multiple shot impacts. Journal of Materials Processing Technology, 2005. 164: p. 1226-1234.

21. Miao, H., et al., On the potential applications of a $3 D$ random finite element model for the simulation of shot peening. Advances in Engineering Software, 2009. 40(10): p. 1023-1038.

22. Gangaraj, S., M. Guagliano, and G. Farrahi, An approach to relate shot peening finite element simulation to the actual coverage. Surface and Coatings Technology, 2014. 243: p. 39-45.

23. Ghasemi, A., et al., Shot peening coverage effect on residual stress profile by FE random impact analysis. Surface Engineering, 2016. 32(11): p. 861-870.

24. Jacob, A., et al., Residual Stress Measurements in Offshore Wind Monopile Weldments using Neutron Diffraction Technique and Contour Method. Theoretical and Applied Fracture Mechanics, 2018.

25. Cozzolino, L.D., et al., Investigation of post-weld rolling methods to reduce residual stress and distortion. Journal of Materials Processing Technology, 2017. 247: p. 243-256.

26. Jenney, C. and A. O'Brien, AWS Welding Handbook. 2001.

27. Karaoğlu, S. and A. Secgin, Sensitivity analysis of submerged arc welding process parameters. journal of materials processing technology, 2008. 202(1-3): p. 500-507.

28. Standards, S., SAE J444, Cast shot and grit size specifications for peening and cleaning, 1993.

29. Abaqus Analysis User's Manual. version 6.12-3, 2012.

30. Goldak, J., A. Chakravarti, and M. Bibby, A new finite element model for welding heat sources. Metallurgical transactions B, 1984. 15(2): p. 299-305.

31. Fu, G., et al., Parameter determination of double-ellipsoidal heat source model and its application in the multi-pass welding process. Ships and Offshore Structures, 2015. 10(2): p. 204-217.

32. Anca, A., et al., Finite element modeling of welding processes. Applied Mathematical Modelling, 2011. 35(2): p. 688-707.

33. Jiang, W., Y. Zhang, and W. Woo, Using heat sink technology to decrease residual stress in $316 \mathrm{~L}$ stainless steel welding joint: Finite element simulation. International journal of pressure vessels and piping, 2012. 92: p. 56-62.

34. Deng, D., FEM prediction of welding residual stress and distortion in carbon steel considering phase transformation effects. Materials \& Design, 2009. 30(2): p. 359-366.

35. Deng, D. and H. Murakawa, Numerical simulation of temperature field and residual stress in multi-pass welds in stainless steel pipe and comparison with experimental measurements. Computational materials science, 2006. 37(3): p. 269-277.

36. Mousavi, S.A. and R. Miresmaeili, Experimental and numerical analyses of residual stress distributions in $T I G$ welding process for 304L stainless steel. journal of materials processing technology, 2008. 208(1-3): $\mathrm{p}$. 383-394.

37. Shan, X., et al., Thermo-mechanical modelling of a single-bead-on-plate weld using the finite element method. International Journal of Pressure Vessels and Piping, 2009. 86(1): p. 110-121.

38. Muránsky, O., et al., The effect of plasticity theory on predicted residual stress fields in numerical weld analyses. Computational Materials Science, 2012. 54: p. 125-134.

39. Mahmoudi, A. H., et al., A comprehensive experimental and numerical study on redistribution of residual stresses by shot peening. Materials \& Design, 2016. 90: p. 478-487. 